\title{
SOBRE LA (IN)CONSTITUCIONALIDAD DEL AUTO ACORDADO QUE REGULA LA TRAMITACIÓN Y FALLO DE LA ACCIÓN DE PROTECCIÓN. UN COMENTARIO A LA SENTENCIA ROL 1557 DEL TRIBUnAL CONSTITUCIONAL
}

\section{Carolina Salas Salazar ${ }^{*}$}

\section{1) ANTECEDENTES}

Este año 2011 el Tribunal Constitucional chileno (TCCh) se ha pronunciado en reiteradas ocasiones sobre la constitucionalidad del Auto Acordado sobre Tramitación y Fallo del Recurso de Protección de las Garantías Constitucionales ${ }^{1}$, dictado por la Corte Suprema el 27 de junio de 1992, de entre ellas, nos haremos cargo en esta oportunidad de la sentencia Rol No 1557, de 14 de abril de 2011. En ella el TCCh desestimó el requerimiento de inconstitucionalidad presentado por Isapre Cruz Blanca, demandada en proceso de protección cuya tramitación pendía ante la Iltma. Corte de Apelaciones de Santiago y el objeto de esta impugnación es el apartado 11 del referido Auto Acordado, que contempla la posibilidad de condenar en costas.

Nadie puede desconocer el grado de importancia que tiene esta normativa en un Estado constitucional de Derecho, al regular el ejercicio de una acción protectora de derechos fundamentales, a lo que se suma el hecho de que la utilización de la atribución del Tribunal Constitucional reconocida en el artículo 93 No 2 de la Constitución aún es de carácter extraordinario, lo que hace que estimemos pertinente y justificado hacer algunas lecturas y análisis con relación a los fundamentos utilizados por el intérprete constitucional para desechar este requerimiento.

\section{1) El VOTO DE MAYORÍA}

El razonamiento del voto de mayoría en la sentencia se articuló en base a cuatro aspectos: en primer lugar se hace cargo de la determinación del conflicto sometido a su conocimiento, en donde reitera su interpreta-

Doctora en Derecho. Profesora de Derecho Constitucional de la Escuela de Derecho de la Universidad Católica del Norte, sede Coquimbo. Correo electrónico: csalas@ucn.cl

Tribunal Constitucional de Chile, sentencias Roles No 1812, 1816 y 1817 todas de 18 de agosto; sentencia Rol No 1870 de 19 de enero y Rol No 1924 de 8 de marzo. 
ción sentada en la sentencia Rol $783^{2}$ al revisar su competencia a la luz de los artículos 93 No 2 y 93 inciso tercero de la Constitución, que entrega legitimación activa a las partes de un juicio o gestión pendiente ante un tribunal ordinario o especial, o desde la primera actuación en el procedimiento penal, cuando esta sea afectada en el ejercicio de sus derechos fundamentales por lo dispuesto en el respectivo auto acordado. Asimismo, revisa con detalle todos los requisitos para su interposición de conformidad a los artículos 52 a 60 de la Ley 17.997, Orgánica Constitucional del Tribunal Constitucional (LOTC), facultad que la doctrina ha calificado como una "queja o amparo de derechos fundamentales"3.

Para el TCCh la afectación a los derechos se produce cuando la aplicación de las disposiciones del auto acordado produce un menoscabo o perjuicio, situación que se trata de evitar a través de la declaración de inconstitucionalidad del auto acordado respectivo o del aspecto específico de él que se impugna ${ }^{4}$ y lo caracteriza como un control abstracto pues produce efectos derogatorios y generales, desligando la afectación de derechos fundamentales del requirente del vicio de inconstitucionalidad del auto acordado impugnado 5 .

En segundo lugar, el Tribunal revisa la facultad de la Corte Suprema para dictar este tipo de normas generales y abstractas, cuya fuente normativa se encuentra en la superintendencia económica que la Carta de 1980 entrega a la Corte Suprema en el artículo 82 en directa relación con el principio de independencia judicial que recoge el artículo $76^{6}$. En este sentido, señala que esta facultad normativa que posee el máximo tribunal del Poder Judicial tiene como fin propender al más eficaz cumplimiento de las funciones jurisdiccionales que le han sido confiadas, y en ese contexto, la superintendencia económica se hace cargo de todo lo que conduzca a la perfecta disposición de los diversos elementos necesarios para la mejor prestación del servicio 7 .

El tercer grupo de argumentaciones dice relación con la facultad de condenar en costas que regula el apartado 11 del auto acordado. En este

2 Tribunal Constitucional de Chile, sentencia Rol 783, de 31 de agosto de 2007. Requerimiento de inconstitucionalidad presentado por María Isabel Reyes Kokisch en contra del Auto Acordado Relativo al Procedimiento a Utilizarse para hacer Efectiva la Responsabilidad Disciplinaria de los Funcionarios y Empleados Judiciales, dictado el 13 de octubre de 1995 por la Corte de Apelaciones de Santiago y publicado en el Diario Oficial de 17 de noviembre de 1995.

3 Aldunate Lizana, Eduardo (2008). Derechos Fundamentales. Santiago: LegalPlubishing, p. 366.

Considerando $14^{\circ}$

Aldunate Lizana, Eduardo (2007). "Sentencia sobre amparo de derechos fundamentales". Revista de Derecho Universidad Austral, Vol. 20, No 2, pp. 221-238, p. 237.

Considerando $9^{\circ}$

Considerando $10^{\circ}$, y a la sazón utiliza un fallo de la Corte Suprema de 1 de septiembre de 1926. 
punto, el TCCh establece que el apartado cuestionado no consagra una regla sobre procedimiento y tramitación, ya que establece una atribución o potestad ya radicada en los Tribunales Superiores, es decir esta es una facultad que ya forma parte de su esfera de competencias en este caso dicha competencia -dice el TCCh- se encuentra radicada en el artículo 20 de la Constitución, ya que se trataría de una de las providencias que la Corte estima necesarias para restablecer el imperio del Derecho y de asegurar la debida protección del afectado. En este sentido, agrega en su considerando decimonoveno, que la condena en costas busca desincentivar al litigante temerario o abusivo. No se trata, entonces, de un instituto sancionatorio abierto que autorice el arbitrio en su determinación.

El cuarto grupo de argumentaciones dice relación con la posible infracción al artículo 19 No 3, inciso quinto, y $26^{\circ}$ de la Constitución. Para ello, luego de conceptuar la noción de debido proceso, estima que "...la condena en costas representa la aplicación del principio general de derecho del vencimiento en juicio, que tiende a precaver la utilización de los procedimientos en forma dilatoria o contraria a la buena fe" 8 . Y que esta no afecta la garantía del debido proceso pues "no es fruto de una apreciación arbitraria por parte del Tribunal"'. La razón para arribar a esta conclusión se esgrime en torno a la definición de costas como consecuencias juridicas derivadas del incumplimiento de cargas procesales... se trata del reembolso de gastos originados en el proceso por la misma parte... no se trata entonces de sanciones, por ende, concluyen los argumentos del TCCh, no hay posibilidad a la arbitrariedad, pues esta facultad es ejercida en el marco del debido proceso $^{10}$.

\section{2) EL VOTO DISIDENTE}

El voto del Ministro Fernández en cambio, se fundamenta en que "...la condena en costas en materia constitucional vulnera el principio constitucional de acceso a la justicia"11 y la tramitación del recurso de protección es un ejemplo de control difuso de constitucionalidad ${ }^{12}$, que se caracteriza por su informalidad ${ }^{13}$, ello impediría que un tribunal pueda apreciar debidamente la negligencia o temeridad en la interposición del recurso, elementos de la tipicidad para la condena en costas, teniendo en cuenta, además, el carácter de suyo subjetivo que tales valoraciones implican ${ }^{14}$.

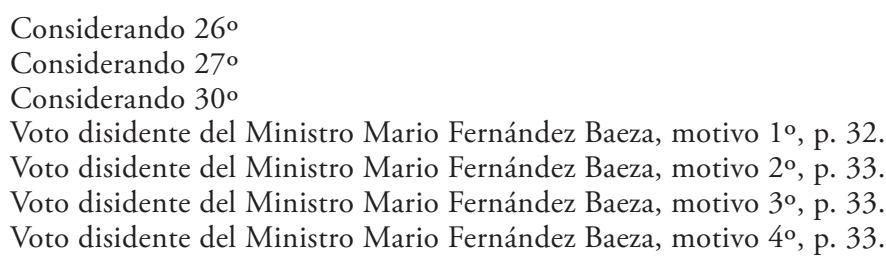


Culmina su voto estableciendo que la justiciabilidad de los derechos que protege la acción de protección no puede encontrarse sometida a una traba con costo pecuniario, hipotética y futura, de apreciación subjetiva con imperio jurisdiccional ${ }^{15}$, ya que ello limitaría la vigencia jurídica efectiva del derecho impetrado.

\section{2) COMENTARio}

\section{1) LA CONSTITUCIONALIDAD DEL AUTO ACORDADO: LAS EXIGENCIAS INTERNACIONALES EN MATERIA DE PROTECCIÓN DE DERECHOS}

Para referirnos al auto acordado que regula la tramitación y procedimiento de la acción de protección, se requiere necesariamente que su estudio sea delimitado por un contexto que nos viene dado por la Convención Americana de Derechos Humanos (CADH), ya que esta en su artículo 25.1 reconoce para todas las personas el derecho a un recurso sencillo y rápido o a cualquier otro recurso efectivo ante los jueces o tribunales competentes, que la ampare contra actos que violen sus derechos fundamentales reconocidos por la Constitución, la ley o la presente Convención, aun cuando tal violación sea cometida por personas que actúen en ejercicio de sus funciones oficiales $^{16}$, la que se encuentra estrechamente relacionada con el artículo 8 de la misma que consagra la garantía del debido proceso, ambas se erigen como una de las piedras basales del sistema de protección de derechos, ya que de no existir una adecuada protección judicial de los derechos consagrados en el ámbito interno de los Estados -ya sea en su legislación interna o en los textos internacionales de derechos humanos-, su vigencia se torna ilusoria ${ }^{17}$.

15 Voto disidente del Ministro Mario Fernández Baeza, motivo 5º, p. 33.

16 El origen poco conocido de esta garantía judicial es latinoamericano, de su consagración originalmente en la Declaración Americana sobre los Derechos y Deberes de Hombre (de abril de 1948) fue trasplantada a la Declaración Universal de los Derechos Humanos de diciembre de 1948, y de ahí a las Convenciones Europea y Americana sobre Derechos Humanos (arts. 13 y 25, respectivamente), así como al Pacto de Derechos Civiles y Políticos. Bajo la Convención Europea de Derechos Humanos, en particular, ha generado una considerable jurisprudencia, a la par de un denso debate doctrinal. Véase Corte Interamericana DE Derechos Humanos (1997). Caso Genie Lacayo, sentencia del 13 de septiembre de 1997, párrs. 18/21, Voto disidente del Juez A.A. Cançado Trindade

17 Tal como lo ha dicho la Corte Interamericana, el derecho a la protección judicial efectiva, "constituye uno de los pilares básicos, no solo de la Convención Americana, sino del propio Estado de Derecho en una sociedad democrática en el sentido de la Convención". CorTe InTERAmericana de Derechos Humanos. Caso Castillo Páez, sentencia del 3 de noviembre de 1977, párr. 82; Caso Suárez Rosero, sentencia del 12 de noviembre de 1997, Serie C, N 35, párr. 65. Lo importante de estas garantías es su pervivencia más allá de los avatares políticos de los Estados. De ahí que la Corte haya dicho que "las garantías sirven para proteger, asegurar o hacer valer la titularidad o el ejercicio de un derecho. Como los Estados Partes tienen 
En este orden de ideas, la Corte Interamericana de Derechos Humanos ha señalado que este derecho "es una garantía judicial fundamental mucho más importante de lo que uno pueda prima facie suponer, y que jamás puede ser minimizada" 18 . En ese entendido, su correcta aplicación tiene el sentido de perfeccionar la administración de la justicia a nivel nacional, con los cambios legislativos necesarios a la consecución de un propósito: el desarrollo de las personas y el perfeccionamiento del sistema democrático.

A partir de estas premisas, y ligado a la garantía del debido proceso, es que el cumplimiento de las obligaciones estatales con relación a este derecho conllevan la necesidad de establecer procedimientos bilaterales, informales, contradictorios, con oportunidades efectivas para ejercer el derecho a la defensa, el derecho a la prueba, el derecho al recurso y el derecho a la motivación de las resoluciones judiciales, cuestiones que en todo caso configuran un "mínimo exigible"19 para el Estado chileno.

Basta entonces con realizar una simple comparación para concluir que el Estado de Chile no cumple con los estándares de protección establecidos por el sistema internacional de protección de derechos humanos. Este tema ha sido latamente señalado por la doctrina nacional ${ }^{20}$, como una situación deficitaria tanto en la forma como en el fondo, lo que convierten al auto acordado objeto de este comentario en un instrumento de dudosa constitucionalidad y a la acción de protección como insuficiente para proteger los derechos de las personas ${ }^{21}$. De allí que el esfuerzo interpretativo que realiza el TCCh por intentar establecer lo contrario, no solo en esta sentencia sino en otras posteriores en las que se intentó impugnar el apartado 7 del referido auto ${ }^{22}$, sea objeto de críticas y comentarios ${ }^{23}$.

la obligación de reconocer y respetar los derechos y libertades de la persona, también tienen la de proteger y asegurar su ejercicio a través de las respectivas garantías, vale decir, de los medios idóneos para que los derechos y libertades sean efectivos en toda circunstancia". COMISIÓN INTEramericana de Derechos Humanos (1987). OC-8/87, 30 de enero, párrafo 25.

18 Corte Interamericana de Derechos Humanos (1997). Caso Genie Lacayo, párrs. 18/21, Voto disidente del Juez A.A. Cançado Trindade.

19 Nogueira Alcalá, Humberto (2004). "Elementos del bloque constitucional del acceso a la jurisdicción y debido proceso proveniente de la Convención Americana de Derechos Humanos", Estudios Constitucionales, año 2, No 1, pp. 123-158.

20 Por todos, Cazor, Kamel / Rojas, Christian (2009). "Las deficiencias y prácticas de la acción de protección”, Revista de Derecho de la Universidad Católica del Norte, año 16, No 1, pp. 169-192.

21 Véase informe sobre el Proyecto de Ley de acciones constitucionales de amparo o hábeas corpus y protección, boletín 2809/07, disponible en http://www.senado.cl/appsenado/templates/tramitacion/index.php\# [Fecha de visita, 21 de octubre de 2011].

22 Véase nota 1.

23 Zúñiga Urbina, Francisco (2011). "Control de constitucionalidad de Autos Acordados". Revista Estudios Constitucionales, ańo 9, No 1, pp. 389-418; Verdugo, Mario (2011). "Inconstitucionalidad por omisión" en http://diarioconstitucional.cl/mostrararticulo. php?id=73\&idautor $=38$ [Fecha de visita: 30 de octubre de 2011]. 
Por ende, la primera cuestión a señalar dice relación con la decisión del TCCh de otorgar una base de constitucionalidad a la potestad normativa de la Corte Suprema ${ }^{24}$, señalando que su objetivo es propender al más eficaz cumplimiento de las funciones jurisdiccionales que le han sido confiadas, con ese objetivo es que puede dictar una regulación de carácter interno que es indispensable para la efectividad del Poder Judicial ${ }^{25}$ y que puede ser definida también como "reglamentos administrativos y jurídicos" 26 , resultado de una especie de potestad de autorregulación que determina la actuación de un órgano público específico, y son asimilables a los Instructivos del Ministerio Público, del Banco Central o a las instrucciones que puede dictar la Administración Pública ${ }^{27}$.

En este punto el Tribunal olvida que las materias de las que se hace cargo el auto acordado impugnado son propias y exclusivas del dominio legal, por ende, ya desde su inicial acercamiento al tratamiento del tema, se desconoce la inconstitucionalidad competencial de que adolece esta normativa, ya que la Carta establece una reserva de ley orgánica y funcional, la que es evidente y que a nuestro juicio se agrava si consideramos que esta normativa infralegal no regula cuestiones que afecten el mero funcionamiento interno de los tribunales de justicia, sino que su objeto de regulación es el ejercicio del derecho a la protección judicial y a la tutela judicial efectiva en cuestiones de derechos fundamentales, estableciendo condiciones y requisitos para su ejercicio, así como la posibilidad de ser condenado en costas, cuando se estime que la petición no es plausible.

En este sentido, resulta curiosa la contradicción en la que cae el intérprete constitucional, ya que en el considerando $14^{\circ}$ establece que los autos acordados "no pueden contradecir normas legales ni menos las de rango constitucional. Por ende, [estos] no pueden regular materias que el constituyente ha reservado al legislador, como ocurre con los derechos fundamentales", de ahí que las argumentaciones posteriores tienen por objetivo desvirtuar la postura del requirente en el sentido de establecer que la condenación en costas no afecta la garantía del debido proceso ni el derecho a la igualdad ante la ley, lo que deja en evidencia la existencia de una postura previa, la que luego el Tribunal intenta sustentar a través de sus argumentos.

Este error en el análisis de los hechos presentados ante el Tribunal tiene que ver con la opción de comprender que el artículo 93 No 2 de la Constitución recoge una atribución de control abstracto que termina por dejar de lado la afectación de derechos fundamentales.

24 Que al igual que en la sentencia Rol 783, fundamenta en argumentos histórico-jurídicos, véase considerandos $8^{\circ}$ a $13^{\circ}$.

Considerandos $10^{\circ}$ y $14^{\circ}$.

ZúNIIga Urbina (2011) 390.

Cabe destacar que en todo caso, estas son fuentes normativas que no se encuentran sometidas a controles de constitucionalidad, lo que evidencia que el principio de supremacía constitucional no alcanza a toda la actuación del poder público como sería deseable. 


\section{2) LA CONDENA EN COSTAS EN EL ÁMBITO DE PROTECCIÓN}

El impugnado apartado 11 del auto acordado, señala que "Tanto la Corte de Apelaciones como la Corte Suprema, cuando lo estimen procedente, podrán imponer la condenación en costas", lo que para el TCCh es una atribución o potestad que dice relación con una 'competencia' que asiste a dichos órganos y no con la 'forma' como han de sustanciar un proceso dado"28. Y prosigue señalando que dicha competencia específica se la otorga el artículo 20 de la Constitución, cuando mandata al tribunal para adoptar "las providencias que juzgue necesarias para restablecer el imperio del derecho y asegurar la debida protección del afectado". Lo que facultaría incluir -de acuerdo con el intérprete constitucional- la condena en costas.

Partamos por establecer que la acción de protección es de naturaleza cautelar, es decir, su objetivo es proteger el goce y ejercicio de derechos fundamentales, restableciendo la situación a la realidad anterior a la afectación de tales derechos ${ }^{29}$, de allí que resulte obvio que las providencias que puedan decretar tanto las Cortes de Apelaciones como la Corte Suprema en virtud del artículo 20 de la Constitución, son medidas cautelares, conservativas o innovativas, ya que son estas las que aseguran en alguna medida la posibilidad de restablecer la situación del afectado al estado inmediatamente anterior a la afectación de sus derechos, las que en todo caso cesan una vez dictada la sentencia definitiva.

Las costas por su parte, tienen por objetivo precaver la utilización de los procedimientos de forma dilatoria o contraria a la probidad o a la buena fe, son una carga impuesta a quien ha litigado de forma desleal o que carece de motivo plausible para hacerlo ${ }^{30} \mathrm{y}$-tal como lo establece el TCCh- son un instrumento idóneo para evitar la litigación infundada o puramente dilatoria, pues discriminan los libelos que carecen de fundamento plausible ${ }^{31}$. De allí que luego concluya que la Corte Suprema no ha contravenido la Constitución al establecer el apartado 11 en el auto acordado, pues ha actuado dentro de su facultad de propender al mejor servicio judicial [evitando litigantes poco probos o negligentes], y por expreso mandato del artículo 20 de la Carta Fundamental, ha incluido en ese cuerpo normativo la facultad de condenar en costas al litigante que ejerce su acción

Considerando $16^{\circ}$

Comisión de Derechos humanos, nacionalidad y ciudadanía de la Cámara de DipuTADOs (2007). "Proyecto de Ley de acciones protectoras de derechos fundamentales", Estudios Constitucionales, año 5, No 1, pp. 491-521, p. 494.

30 Considerando $18^{\circ}$

31 Considerando $19^{\circ}$, en alusión a la sentencia rol 1345, de 25 de mayo de 2009. Pronunciamiento de oficio sobre la inconstitucionalidad de las expresiones: "Para dar curso a ellos se exigirá que el infractor acompañe el comprobante de haber pagado la multa", contenidas en el inciso primero del artículo 171 del Código Sanitario. 
de manera abusiva, infundada, temeraria o contrariando los principios de buena fe y probidad ${ }^{32}$.

Al ser un control abstracto, el Tribunal desconoce totalmente que quien fue objeto de la condena en costas fue la parte recurrida en la acción de protección, quien tiene una actuación bastante limitada de conformidad con el mismo auto acordado, de tal manera que las definiciones procesales de litigación abusiva, infundada o temeraria aducidas en la sentencia quedan un poco fuera de lugar. En abstracto, no se produce afectación a derechos fundamentales, y se desconoce la situación fáctica que lleva precisamente a la presentación del requerimiento, generando un escenario difícil de comprender en un Estado constitucional.

Por otra parte, aun cuando pudiésemos encontrar la habilitación constitucional que justifica la potestad de la Corte Suprema para regular a través de autos acordados esta situación, debemos recordar también que los derechos fundamentales no solo son límites a la actuación del poder público, sino también mandatos de actuación que le indican al Supremo Tribunal cómo debe legislar al momento de establecer los parámetros básicos para la sustentación de un proceso de protección, lo que en la especie no sucede.

\section{3.) La infracción al DEBIDo Proceso}

El debido proceso es un requisito de configuración de un Estado de Derecho $^{33}$. Y desde la óptica procesal, comprendemos que forman parte de este concepto "todas las garantías relativas a la formación del juicio, es decir, a la recolección de prueba, al desarrollo de la defensa y a la convicción del órgano judicial" 34 . La noción fundamental de debido proceso es la de justicia, es decir, que la decisión jurisdiccional sea el resultado de un proceso justo. Esta es una garantía que tiene por objetivo asegurar el máximo grado de racionalidad de la decisión jurisdiccional y su desarrollo va más allá del respeto a la ritualidad de los procedimientos, y su comprensión tiene que ver con respetar la supremacía con que son concebidos los derechos fundamentales en la actualidad.

De hecho, la constitucionalización del proceso sufrido en los últimos lustros permite dar un paso más allá y advertir que esta es una herramienta al servicio de los derechos de las personas, y ya no se le asigna un fin por sí mismo y con ello no decimos que el proceso abandone el rol que permite ejercer los derechos materiales; ni que haya perdido su condición

Considerando $21^{\circ}$

Medina, Cecilia (2003). La Convención Americana: teoría y jurisprudencia. Vida, integridad personal, libertad personal, debido proceso y recurso judicial, Santiago: Centro de Derechos Humanos, Facultad de Derecho, Universidad de Chile, p. 267.

34 Ferrajoli, Luigi (2005). Derecho y razón, Madrid: Trotta, pp. 539 y 540. 
de modelo técnico; se trata simplemente de advertir que su fisonomía debe resultar permeable a las exigencias del tiempo en que ocurre, de forma tal que no sea un mero procedimiento, sino una garantía esencial para los derechos humanos. Ello supone la necesidad de crear condiciones de lo que "es debido", tarea que a mi juicio comparten tanto el legislador, al adoptar decisiones político-legislativas, el juez ordinario, y el Tribunal Constitucional que lo ha conceptuado en varias oportunidades ${ }^{35}$.

A partir de ello, la sentencia se limita a revisar la eventual arbitrariedad que permitiría el apartado 11, para lo cual justifica que la aplicación de las costas por parte de los tribunales no es el resultado de una arbitrariedad, pues su base se encuentra en las diversas actuaciones del procedimiento que ilustran la decisión final del juzgador ${ }^{36}$. Desde su perspectiva, las costas no son sanciones propiamente tales y por ello que no se les aplica el estándar de racionalidad y justicia de la medida, ya que esta es una posibilidad a la que cualquier litigante puede verse expuesto, ya que dependiendo del desarrollo del procedimiento, puede quedar en evidencia un actuar negligente o carente de plausibilidad que lo haga acreedor a la condena en costas en la sentencia definitiva ${ }^{37}$. Pero dejemos claro que la condena en costas es una sanción, cuando habla de consecuencias jurídicas el intérprete olvida que las sanciones son una especie de consecuencia y que puede haber a su vez muchos tipos de sanciones.

Sobre su inconstitucionalidad, resulta clarificador el voto disidente del ministro Fernández, al señalar que el carácter informal de la acción de protección, impide apreciar debidamente la negligencia o temeridad en la interposición del recurso, opinión que compartimos. Y la sola posibilidad de que pueda aplicarse es -en abstracto- atentatoria al debido proceso, pues, como ya sabemos, esta decisión es impuesta en la sentencia definitiva, sin posibilidad de que las partes se defiendan, como puede ocurrir con su tratamiento incidental en los procedimientos civiles ordinarios, lo que agudiza el riesgo de que finalmente sea una apreciación arbitraria por parte del Tribunal, tal como al parecer ocurre en la especie, toda vez que

35 Véase sentencias Rol 478, de 8 de agosto de 2006. Requerimiento de inaplicabilidad presentado por Guido Girardi Lavín respecto del inciso tercero del artículo 416 del Código Procesal Penal, en la causa rol No 2257-2006 que se sigue ante la Corte de Apelaciones de Santiago; Rol 481, de 4 de junio de 2006. Requerimiento de inaplicabilidad presentado por Inversiones Errázuriz Limitada, respecto de los artículos 250 del Código de Procedimiento Civil, y los artículos 215, 217, 218 inciso segundo, 219 y 221 inciso primero, todos del Código Orgánico de Tribunales, en la causa caratulada "State Street Bank and Trust Company con Inversiones Errázuriz Limitada y otros", rol No 2349-2005 que se sigue ante la Corte Suprema; y Rol 1130, de 7 de octubre de 2008. Requerimiento de inaplicabilidad deducido por Carolina Gajardo Salazar respecto del inciso segundo del artículo 387 del Código Procesal Penal, en la causa RIT N ${ }^{\circ}$ 2015-2005, seguida ante el Juzgado de Garantía de Talcahuano, por cuasidelito de homicidio, todas ellas citadas en los considerandos $24^{\circ}$ y $25^{\circ}$.

36 Considerando $27^{\circ}$

37 Considerando $28^{\circ}$ 
el condenado en costas es la parte recurrida que originó la afectación en el ejercicio de derechos de un particular, en donde la condena en costas se parece bastante a una sanción. Además, si la decisión de condenar en costas es adoptada por la Corte Suprema, esta no puede ser objeto de recurso alguno.

Al parecer, todos los errores interpretativos en los que incurre el TCCh en esta sentencia tienen que ver con que la atribución de controlar la potestad normativa de la Corte Suprema debiera ser un ejemplo de control concreto, ya que lo contrario -el control abstracto- le impide apreciar la verdadera afectación de derechos fundamentales, tal como se lo exige la Constitución.

Finalmente, cabe señalar que al contar con varias decisiones relacionadas con la (in)constitucionalidad del auto acordado sobre tramitación y fallo de la acción de protección, es bueno recordar que esta normativa tenía un carácter supletorio, en tanto el legislador cumplía su cometido. Esta inercia legislativa, para algunos configura una omisión ${ }^{38}$, la que se torna más grave si consideramos que existe un proyecto de ley de acciones constitucionales protectoras de derechos fundamentales que aún se mantiene en primer trámite constitucional, lo que nos augura un futuro poco alentador pues seguiremos recibiendo y criticando una línea jurisprudencial que dudosamente se ajusta a las expectativas que genera un sistema democrático.

\section{BIBLIOGRAFÍA}

Aldunate Lizana, Eduardo (2007). "Sentencia sobre amparo de derechos fundamentales". Revista de Derecho Universidad Austral, Vol. 20, No 2, pp. 221-238, p. 237. p. 366.

(2008). Derechos Fundamentales. Santiago: LegalPlubishing,

(2009). Jurisprudencia Constitucional 2006-2008. Estudio selectivo. Santiago: LegalPlubishing.

Cazor, Kamel / Rojas, Christian (2009). "Las deficiencias y prácticas de la acción de protección", Revista de Derecho de la Universidad Católica del Norte, año 16, No 1, pp. 169-192.

Ferrajoli, Luigi (2005). Derecho y razón, Madrid: Trotta.

Medina, Cecilia (2003). La Convención Americana: teoría y jurisprudencia. Vida, integridad personal, libertad personal, debido proceso y recurso judicial, Santiago: Centro de Derechos Humanos, Facultad de Derecho, Universidad de Chile, p. 267.

38 Verdugo (2011) 
Nogueira Alcalá, Humberto (2004). "Elementos del bloque constitucional del acceso a la jurisdicción y debido proceso proveniente de la Convención Americana de Derechos Humanos", Estudios Constitucionales, año 2, No 1, pp. 123-158.

Verdugo, Mario (2011). "Inconstitucionalidad por omisión” en http:// diarioconstitucional.cl/mostrararticulo.php?id=73\&idautor $=38$ [Fecha de visita: 30 de octubre de 2011].

Zúñiga Urbina, Francisco (2011). "Control de constitucionalidad de Autos Acordados". Revista Estudios Constitucionales, año 9, No 1, pp. 389-418. 